\title{
ERRATUM
}

\section{Resonant enhancement of electron energy by frequency chirp during laser acceleration in an azimuthal magnetic field in a plasma}

K.P. SINGH ${ }^{1}$ AND H.K. MALIK ${ }^{2}$

${ }^{1}$ Simutech, Gainesville, Florida

${ }^{2}$ Plasma Waves and Particle Acceleration Laboratory, Department of Physics, Indian Institute of Technology Delhi, New Delhi, India

(Volume 26, Number 3, 2008, pages 363-369; doi:10.1017/S0263034608000372)

The left-hand running head should read as follows:

K.P. Singh \& H.K. Malik 